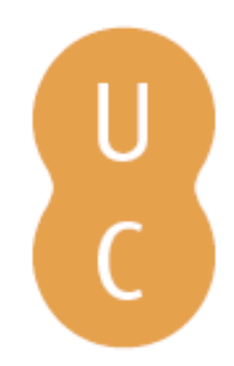

\title{
nommalina
}

\section{Planeamento urbano e financiamento das autarquias: o estado (des)regulador da expansão urbana?}

\author{
Autor(es): $\quad$ Gonçalves, Carlos \\ Publicado por: Imprensa da Universidade de Coimbra \\ URL \\ persistente: URI:http://hdl.handle.net/10316.2/30809 \\ DOI: $\quad$ DOI:http://dx.doi.org/10.14195/978-989-26-0244-8_36 \\ Accessed : $\quad$ 26-Apr-2023 14:24:59
}

A navegação consulta e descarregamento dos títulos inseridos nas Bibliotecas Digitais UC Digitalis, UC Pombalina e UC Impactum, pressupõem a aceitação plena e sem reservas dos Termos e Condições de Uso destas Bibliotecas Digitais, disponíveis em https://digitalis.uc.pt/pt-pt/termos.

Conforme exposto nos referidos Termos e Condições de Uso, o descarregamento de títulos de acesso restrito requer uma licença válida de autorização devendo o utilizador aceder ao(s) documento(s) a partir de um endereço de IP da instituição detentora da supramencionada licença.

Ao utilizador é apenas permitido o descarregamento para uso pessoal, pelo que o emprego do(s) título(s) descarregado(s) para outro fim, designadamente comercial, carece de autorização do respetivo autor ou editor da obra.

Na medida em que todas as obras da UC Digitalis se encontram protegidas pelo Código do Direito de Autor e Direitos Conexos e demais legislação aplicável, toda a cópia, parcial ou total, deste documento, nos casos em que é legalmente admitida, deverá conter ou fazer-se acompanhar por este aviso.

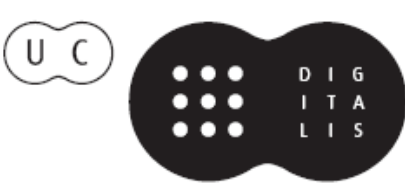




\section{TRUNFOS DE UMA}

\section{EOGRAFIA ACIVA}

\section{DESENVOLVIMENTO LOCAL,}

AMBIENTE,

ORDENAMENTO

E TECNOLOGIA

Norberto Santos

Lúcio Cunha

COORDENAÇÃO 
Carlos Gonçalves

Instituto de Geografia e Ordenamento do Território

\section{PLANEAMENTO URBANO E FINANCIAMENTO DAS AUTARQUIAS: \\ O ESTADO (DES)REGULADOR DA EXPANSÃO URBANA?}

\section{INTRODUÇÃO}

A administraçáo tem um papel central na regulação do mercado imobiliário. Mesmo quando não o exerce. Neste campo não há lugar a vazios de poder. A Administração tem a seu cargo a punição pela prossecução do interesse público na transformação do território. Este conceito tem assumido contornos fluidos que são aproveitados pela acção dos particulares. O quadro legal (quer o RJIGT quer a Lei de Solos) é palco deste tipo de situação. Introduzem-se ciclos de acção/reacção que tendem para a delegação da prossecução do interesse público para a esfera dos particulares. O mecanismo colocado nos PIN é um exemplo disto. Estes mecanismos (contratualização) têm acoplado, problemas diversos, nomeadamente, ocupação desordenada (por vezes clandestina), subjugação de outros recursos (naturais) ou disfuncionalidades na relação urbano/rural (com especial incidência nas áreas de expansão).

O estabelecimento de regras de uso do solo são, primeiramente, garante de transparência, mas também deveria servir para introduzir princípios de repartição justa de maisvalias. De implementação difícil, a solução apresentada tem sido "planear com o mercado".

Regular com os instrumentos de tributação é uma fórmula paralela à anteriormente apresentada, embora, no caso português sáo vários os autores que defendem que esta actuação apresenta-se pela sua ineficácia. Porventura, serve-se mais da urbanizaçáo do que serve para a controlar/regrar e distribuir as receitas que esta gera.

\section{OS PLANOS E A (DES)REGULAMENTAÇÃO DO INTERESSE PÚBLICO NO QUADRO LEGAL}

Referindo-se aos princípios fundamentais da Administração Pública, a Constituição da Republica Portuguesa inscreve no seu artigo $266 .^{\circ}$ que «a persecução do interesse público, no respeito pelos direitos e interesses legalmente protegidos dos cidadãos» é um princípio basilar da actuação da administração. Refere ainda que os direitos dos cidadãos (que devem ser perseguidos para se dar cumprimento ao interesse público), são o respeito pelo princípio da igualdade, da proporcionalidade, da justiça e da imparcialidade. 
Atentando à formulação constante no no 4 da Lei no 48/98 de 11 de Agosto obtém-se a indicação de que as autarquias locais, em cumprimento das suas funçóes, devem prosseguir a articulação de políticas que respeitem o interesse público indo ao encontro das liberdades e garantias dos cidadáos. De igual modo, o Decreto-Lei 380/99 (o primeiro a regulamentar a Lei de Bases do Ordenamento do Território e Urbanismo), subscreve a vinculaçáo da acção do planeamento ao interesse público, remetendo as intervençóes para o estabelecimento de «medidas de tutela dos interesses públicos prosseguidos onde devem ser explicitados os respectivos efeitos, designadamente quando as medidas condicionem a acção territorial de entidades públicas e particulares». No ponto seguinte do mesmo diploma, diz-se que «as medidas de protecção dos interesses públicos estabelecidas nos instrumentos de gestão territorial constituem referência na adopção de quaisquer outros regimes de salvaguarda».

\section{O MERCADO IMObiliário E O FinANCIAMENTO DAS AUTARQUias EM PORTUGAL CONTINENTAL}

Através da Lei de Finanças Locais (Lei 2/2007 de 15 de Janeiro), o Estado define os termos do financiamento das autarquias portuguesas. Os municípios assentam a estrutura das suas receitas, tendo por base o Classificador Económico das Receitas das Autarquias Locais aprovado pelo Decreto-Lei n. ${ }^{\circ}$ 26/2002, de 14 de Fevereiro, num conjunto extenso de rubricas.

Do conjunto de tipos de receitas correntes, destacam-se as que se reportam aos impostos directos e as que dizem respeito às transferências da administração central. A transferência por via dos fundos, corresponde à participação dos Municípios nas receitas do Estado. Existem três tipos de Fundos, o Fundo de Base Municipal ${ }^{1}$, o Fundo Geral Municipal $^{2}$ e o Fundo de Coesão ${ }^{3}$.

A adopção desta forma de financiamento permite que se equacione a tese de que pelo menos, em certa parte, o (des)ordenamento do território português, associado a modelos de expansão insustentáveis e especulativos, radique na lógica do sistema de financiamento autárquico. Nesta leitura, os municípios seriam estimulados para o licenciamento urbanístico, contribuindo para o sobreaquecimento artificioso da oferta de imobiliário desproporcionado face às necessidades e à sustentabilidade do território. Esta política irracional seria determinada, segundo aquela tese, pelo apetite ou necessidade municipal de gerarem receitas urbanísticas, importantes para o financiamento da actividade autárquica.

Um outro aspecto, que não será aqui tratado, mas que não raras vezes é coadjuvante com o ponto de vista anterior, prende-se com a sugestáo recorrente da existência de uma plêiade de interesses, relacionados com a corrupção e o financiamento partidário, desenca-

${ }^{1}$ O Fundo de Base Municipal visa dotar os municípios de capacidade financeira mínima para o seu funcionamento, sendo repartido igualmente por todos

${ }^{2} \mathrm{O}$ Fundo Geral Municipal visa dotar os municípios de condiçóes financeiras adequadas ao desempenho das suas atribuições em funçáo dos respectivos níveis de funcionamento e investimento.

${ }^{3}$ O Fundo de Coesão Municipal visa reforçar a coesão municipal, fomentando a correcção de assimetrias, em benefício dos municípios menos desenvolvidos e é distribuído com base nos índices de carência fiscal e de desigualdade de oportunidades, os quais traduzem situaçōes de inferioridade relativamente às correspondentes médias nacionais 
deando estratégias de urbanismo oportunista, que de um modo geral, subjugam os princípios de planeamento e compelem para modelos dispersivos de urbanização.

Importa, antes do mais, precisar o que se entende por "receitas urbanísticas" apuradas num município e, seria de igual modo relevante, perceber qual o saldo entre as receitas e as despesas com o processo de urbanização (especialmente no caso da expansão urbana dispersiva). Também este segundo aspecto não cabe, no já largo comprimento de banda desta dissertação. No entanto, temos que referir que a contabilidade autárquica não está orientada para equacionar rácios desta natureza, desde logo, porque as despesas e as receitas conotadas com a urbanizaçáo do território não sáo temporalmente coincidentes, mas também porque a gestão municipal não se rege pelas regras da racionalidade económica. Isto é, as autarquias não são empresas, por isso não têm necessidade, não têm capacidade, ou não têm interesse em confrontar as receitas do licenciamento de fogos (especialmente em contexto de urbanização dispersiva) com os custos que isso acarreta.

A partir de 1988, quando se substituiu a anterior Contribuição Rústica e Urbana pela Contribuição Predial Autárquica, passando a receita a ser cobrada pelos municípios que poderiam usá-la para custear os seus custos com investimentos, a Administração Central colocou ao dispor das autarquias um instrumento que muitas vezes é usado como catalisador de investimentos imobiliários. Colocando sob a égide dos municípios o estabelecimento da taxa a cobrar, (primeiramente entre o intervalo 1,1 e 1,3\% do valor tributável e mais recentemente entre os 0,4 e os $0,8 \%$ ) estes fazem uso dela como instrumento de competitividade territorial esmagando a taxa como forma de atrair "investimentos" (construção) e com isto cobrar mais impostos.

Referimo-nos apenas à pressão para o licenciamento de fogos, que não deve ser confundido com outros tipos de licenciamento, também eles relacionados com o processo de expansão urbana, como por exemplo o licenciamento de superfícies comerciais, onde para além dos impostos, se negoceiam (de acordo com os casos e mediante a capacidade estratégica e negocial dos autarcas) importantes contrapartidas. Acautelando as incorrecçóes que sempre resultam das generalizaçóes, acompanhamos a conclusão preconizada por Correia (2002): "os municípios com taxas elevadas de crescimento urbano têm procurado aumentar as suas receitas através das taxas (de urbanização e de licenciamento de construção) que lhes permite fazer face aos elevados custos de infra-estruturas e equipamento municipal”. No ponto seguinte procuramos apresentar alguma informaçáo passível de atestar esta realidade.

\section{TRIBUTAÇÃO, FINANCIAMENTO DAS AUTARQUIAS E EXPANSÃO URBANA EM PORTUGAL CONTINENTAL}

De modo a percepcionar o processo de expansão urbana pelo lado das receitas que a partir dela se geram, cartografou-se o peso que a cobrança da SISA em conjunto com o IMI, têm no total das receitas correntes dos municípios tendo por referência o ano de 2005 (Figura 1).

Numa primeira leitura ao mapa ressalta a colagem do corredor litoral, onde tem lugar a maior dinâmica demográfica, bem assim, a maior pressão construtiva, às classes onde estas fontes de receita superam os 30\% do total. Assim, no corredor de Caminha até Setúbal só oito concelhos não se posicionam neste patamar (Estarreja; Vagos; Mira; 
Figura 1 - Representatividade do produto da SISA e IMI no cômputo das receitas correntes dos municípios (2005)

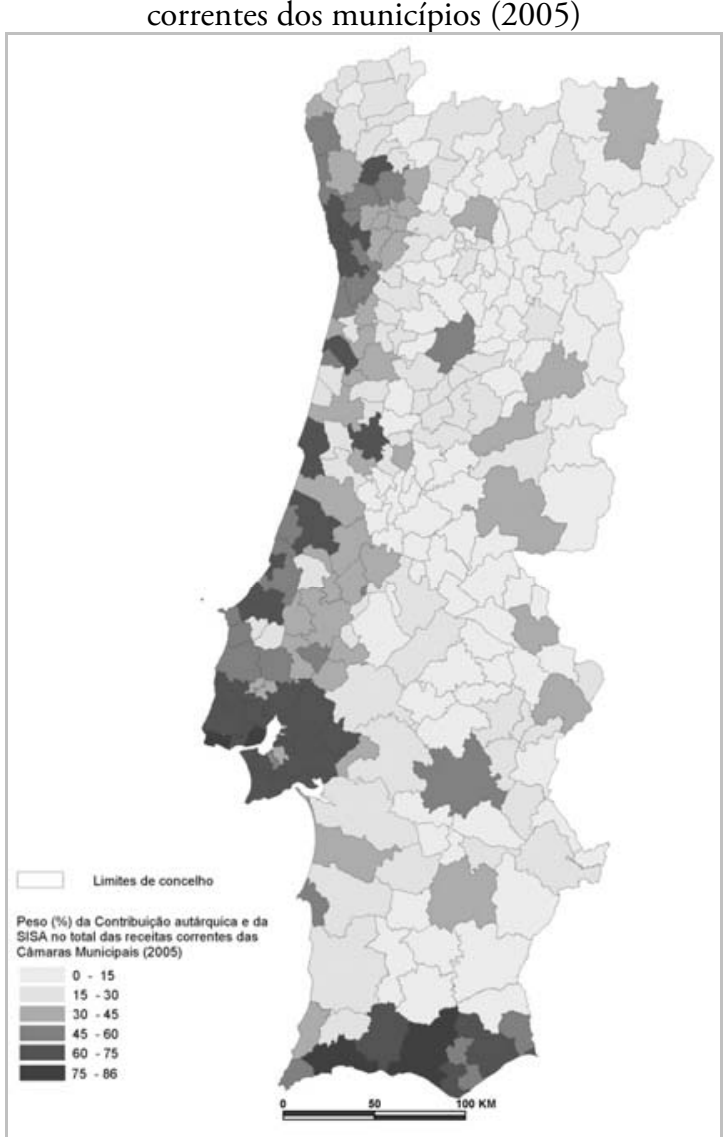

Fonte: INE com tratamento próprio

Figura 2 - Distribuição proporcional (\%) dos concelhos pelas classes de representatividade da SISA e Contribuição Autárquica, no total das receitas correntes

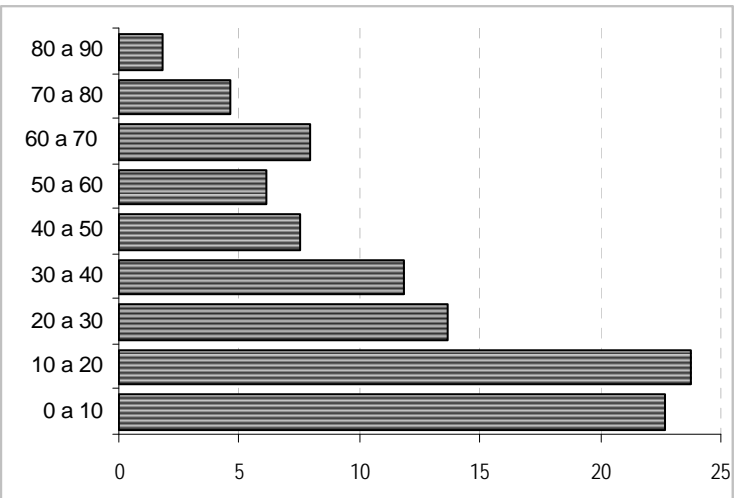

Fonte: INE com tratamento próprio 
Figura 3 - Taxa de variação (\%) do conjunto das receitas SISA e

Contribuição Autárquica entre 1995 e 2005

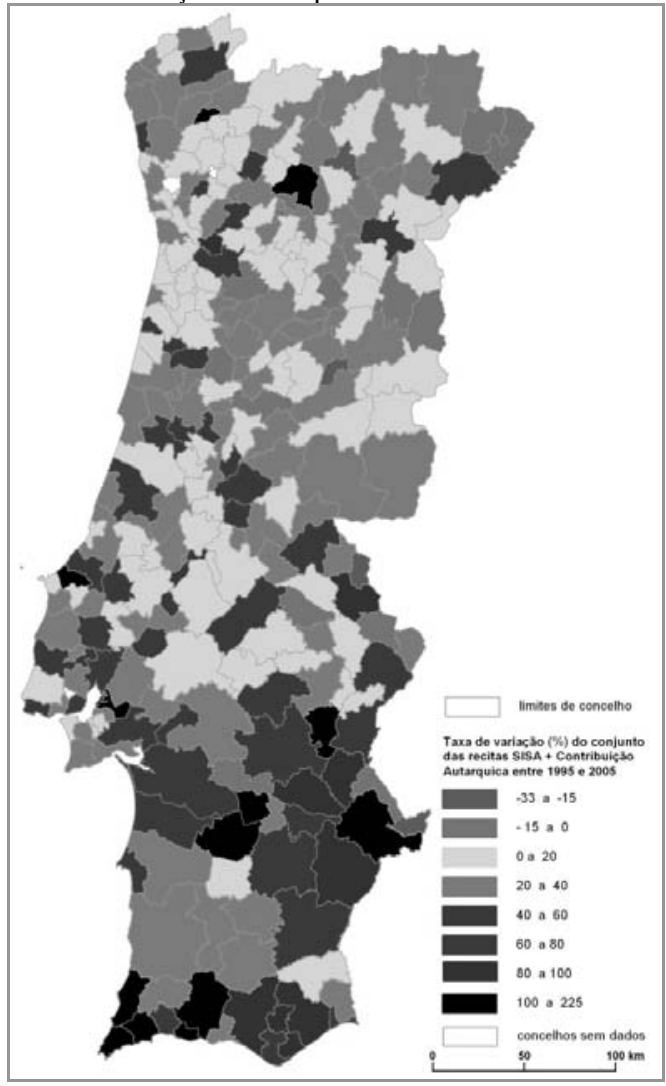

Fonte: INE, com tratamento próprio

Figura 4 - Distribuição dos concelhos por classes respeitantes à taxa de variação do produto da SISA e da Contribuição Autárquica entre 1995 e 2005

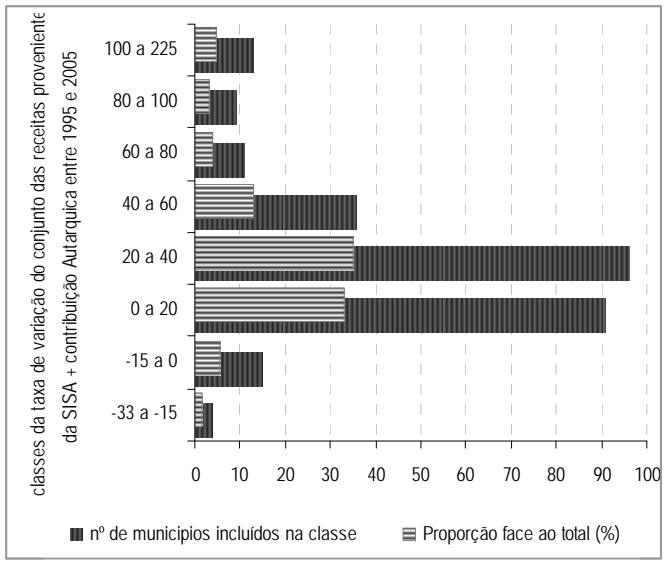

Fonte: INE, com tratamento nosso 
Montemor-o-Velho; Soure; Porto de Mós; Bombarral e; Cadaval). Destaca-se ainda o facto de nos concelhos das Áreas Metropolitanas (a que se juntam Óbidos, Calda da Rainha, Nazaré, Leiria, Figueira da Foz, Coimbra e Aveiro) e o corredor entre Vila Real de Santo António a Vila do Bispo, no Algarve, o peso deste tipo de receita superar os 50\%.

No interior do país a representação desta variável ganha importância nas capitais de distrito onde o parque edificado garante boa parte das receitas correntes.

Tal como se pode verificar no Figura $1 \mathrm{em} 28 \%$ dos concelhos do Continente (57) esta fonte de receita garante mais de $40 \%$ dos fundos disponíveis pelos municípios. Para além da situação verificada no ano de 2005 , representou-se a dinâmica crescente que esta fonte de receita tem conhecido no "bolo" dos orçamentos camarários nos dez anos anteriores.

Desta análise destacamos o facto de em $93 \%$ dos concelhos a taxa de variação na década observada foi positiva. Em $60 \%$ dos concelhos (165) a variaçáo foi superior a $20 \%$ e em cerca de $1 / 4$ a variação foi superior a $40 \%$. Note-se ainda que em 33 concelhos $(12 \%$ o crescimento desta receita foi superior a $60 \%$ assinalando-se treze $\operatorname{casos}^{4}(4,7 \%)$ onde a variação foi superior a 100\% (Figura 3 e 4).

Este conjunto de concelhos protagonistas da situação extrema, à excepção de Amares (certamente relacionado com a frente de expansão da AMP), de Vila Real (configurando um exemplo do resultado da polarizaçáo exercida por uma cidade média face à envolvente projectando um vasto espaço de expansão, nomeadamente junto das grandes superfícies comerciais recentemente instaladas) ou de Alcochete (reflectindo o entesouramento proveniente do volume de construçáo potenciado pela existência da ponte Vasco da Gama inaugurada em 1998).

Os restantes concelhos indiciam processos de aumento exponencial na cobrança de impostos, tendo como fonte o parque imobiliário recentemente instalado, ligado à pressão turístico-residencial. Encaixam nesta tipologia os casos de Óbidos onde se licenciaram vários resortes neste intervalo de tempo, os concelhos alentejanos localizados na envolvente imediata, ou próxima, da Barragem do Alqueva, ou ainda, e para finalizar, os concelhos do barlavento algarvio.

\section{CONCLUSÓES}

A expansão urbana é um fenómeno sentido a várias escalas. Note-se que, no cômputo da EU 75\% da população vive em áreas urbanas, tendo-se verificado nos últimos anos uma expansão na ordem dos 5\%/ano. A tendência de aumento da área de intervenção do urbano é facilitada pelas novas práticas quotidianas e pelo uso crescente do transporte individual. Nos últimos 25 anos aumentou $25 \%$ as áreas urbanizadas ao passo que o aumento da populaçáo foi apenas de $6 \%$. Em Portugal, o fenómeno tem assumido contornos de grande visibilidade das últimas décadas. (muitas vezes diagnosticado nos vários relatórios dedicados ao padrão de povoamento). A crescente dilatação da abrangência da Áreas Metropolitanas é acompanhada da atracção e dispersão em torno das cidades médias. Os aglomerados com menos de 2000 habitantes perdem população e os com mais de 10000 aumentam o contingente demográfico.O declínio da população rural foi da ordem

\footnotetext{
${ }^{4}$ (Amares, Vila Real, Óbidos, Alcochete, Redondo, Alvito, Ferreira do Alentejo, Moura, Aljezur, Vila do Bispo, Lagos, Lagoa e Silves
} 
dos -3,6\% entre 2000 e 2005. Configura-se assim a Grande Área Metropolitana do Litoral (entre a AMP e a AML) na qual vivia, em 2007, 56\% da população, registando uma taxa de crescimento de $11 \%$ ao ano.

A área artificializada aumentou $39 \%$ sendo a progressão na malha descontínua $(29,7 \%)$ superior à verificada ano tecido contínuo $(14,9)$. A taxa de variaçáo do espaço urbanizado foi cerca 11 vezes superior à taxa de variação a populaçáo entre 2005 e 2007. O mercado residencial reflecte esta progressão. Note-se que $76 \%$ das construçóes licenciadas em 2007 (segundo o INE) destinam-se à habitação. Nos últimos 26 anos construíram-se cerca de 1,5 milhôes de fogos, ao ritmo de 59000 novos fogos/ano. Na maior parte dos concelhos, os últimos anos foram marcados por variaçóes no número de alojamentos na ordem dos $20 \%$. Esta situação reforçou-se sobretudo nas coroas das Áreas metropolitanas. Em 2007 o número de alojamentos supera em cerca de 32\% o número de famílias. Os alojamentos cresceram a um ritmos de 2,5\%/ano desde $1981^{\text {a }}$ passo que este indicador foi de 1,3\%/ano no caso das famílias.

A difusão dos instrumentos de planeamento/uso do solo municipal não reproduziram qualquer efeito no desequilíbrio entre a construção de fogos e a progressão demográfica, estando esta mais relacionada com a flutuação espectável nos preços pressentida por parte dos agentes da oferta. As receitas das autarquias relacionam-se com a expansão do seu parque construído. Em 60\% dos concelhos a variação das receitas dos impostos mais relacionados com o processo de urbanizaçáo foi positiva. Note-se, para finalizar, que em $60 \%$ dos municípios a variação entre 1995 e 2005 foi superior a $60 \%$ e em cerca de $1 / 4$, esta superou os $40 \%$.

\section{REFERÊNCIAS BIBLIOGRÁFICAS}

Alves, R. M. (2007). Politicas de Planeamento e Ordenamento do Território no Estado Português. Lisboa: Fundação Calouste Gulbenkian.

Borges, et al. (2003). Mais e Menos Valias (3a ed.). Lisboa: Área Editores.

Correia, P. V. (2003). Poder de Decisão sobre a classificação dos usos do solo e a regulação da oferta e dos preços do imobiliário. Conferências "Ordenamento do Território e Revisão dos PDM", (pp. 1-4). Figueira da Foz.

Correia, P. V. (2002). Políticas de solos no planeamento municipal (2a ed.). Lisboa: Fundação Calouste Gulbenkian.

Carvalho, J. M. (2005). Planeamento urbanistico e valor imobiliário. Cascais: Principia Editora.

Rebelo, E. M. (2005). Modelos de avaliação imobiliária e fundiária aplicados ao mercado de escritórios. Estudos Regionais, 7, pp. 43-64.

Santos, B. d. (1984). O Estado, o Direito e a questấo urbana. Revista Crítica de Ciências Sociais, no 9, pp. 9-86. 